\title{
Determination of Dopamine in Presence of Uric Acid at Poly (Eriochrome Black T) Film Modified Graphite Pencil Electrode
}

\author{
Umesh Chandra, Bahaddurghatta Eshwaraswamy Kumara Swamy ${ }^{*}$, Ongera Gilbert, Sathish Reddy, \\ Bailire Sheena Sherigara \\ Department of PG Studies and Research in Industrial Chemistry, Kuvempu University, Karnataka, India \\ E-mail: kumaraswamy21@yahoo.com \\ Received December 26, 2010; revised April 1, 2011; accepted April 2, 2011
}

\begin{abstract}
A simple commercial graphite pencil electrode was used to investigate the electrochemical oxidation of dopamine. The electropolymerised film of eriochrome black $\mathrm{T}$ was prepared on the surface of graphite pencil electrode by using cyclic voltammetry technique. The prepared electrode exhibits an excellent electrocatalytical activity towards the determination of dopamine. The effects of concentration, $\mathrm{pH}$ and scan rate were investigated. Simultaneous detection of dopamine and uric acid was investigated by using both cyclic voltammetric and differential pulse voltammetry technique. The modified electrode was also used for the detection of dopamine in injection.
\end{abstract}

Keywords: Poly (Eriochrome Black T), Graphite Pencil Electrode, Dopamine, Uric Acid, Cyclic Voltammetry, Differential Pulse Voltammetry

\section{Introduction}

Dopamine is an important neurotransmitter in the amygdala, a phylogenetically older structure of the brain, which is thought to play a critical role in limbic, cognitive and neuroendocrine functions [1,2]. Serious diseases such as Schizophrenia and Parkinsonism may result by loss of DA-containing neurons [3-8]. Patient with this disease shows a low level of DA. Therefore, determination of DA concentration has become important. Many methods were introduced to determine DA, such as spectroscopy, chromatography and electrochemistry [9-13]. Because of its electrochemical activity, DA can also be determined with electrochemical method [7,14]. Uric acid (UA) is the primary end product of purine metabolism in the human body [15]. In a healthy human being, the typical concentration of UA in urine is around $2 \mathrm{mM}$ and in the blood is in between $120 \mu \mathrm{M}$ to $450 \mu \mathrm{M}$ ranges $[16,17]$. Extreme abnormalities of UA levels are symptomic of several diseases, such as, cardiovascular disease [18], hyperuricaemia, uric acid stones [19], gout and Leseh-Nyhan syndrome [20]. Thus accurate determination of UA concentration is of great importance. Recently, electrochemical sensors have attracted much attention due to their advantages of simplicity, cheapness, fast analysis along with high sensitivity and selectivity [21]. The oxidation potential of DA and UA are very close such that, the bare electrode often suffers from fouling effects. The chemically modified electrodes have the ability to detect both DA and UA selectively [22,23].

The electropolymer film coated electrodes are playing an important role in sensor field. Ongera et al. studied the simultaneous determination of dopamine in presence of ascorbic acid at electropolymer modified carbon paste electrode [3,4,21]. Gabriela Broncova et al. used poly (neutral red) modified electrode for determination of citrate in soft drinks [24]. M. Pandurangachar et al. prepared poly (patton's and reeder's) film coated carbon paste electrode for simultaneous detection of dopamine [7]. Sarah M. Kirwan studied the electrochemical properties of AA and $\mathrm{H}_{2} \mathrm{O}_{2}$ at Poly (o-phenylenediamine) film modified Platinum-iridium electrodes alloy wires [25].

In the present work, poly (EBT) film coated graphite pencil electrode is used for the selective detection of DA in the presence of UA. The electrochemical study of EBT was done by our research group [26]. Many electrochemical experiments have been done by electropolymerizing the EBT indicator and discussing their voltam- 
metric behavior by modifying at glassy carbon electrode [27-29]. The structure of EBT was shown in Scheme 1. The graphite pencil electrode (GPE) has been successfully applied to analyses of certain compounds in recent years [30-34]. The GPE is relatively new type of carbon electrode, it is less expensive, more convenient, and renewable compare to the commonly used CPE or GCE [35]. The electropolymerization film of eriochrome black $\mathrm{T}$ (EBT) was coated on the surface of GPE by cyclic voltammetry $(\mathrm{CV})$. The electrode had high concentration of negative-charged function group $-\mathrm{SO}_{3}^{-}$and electron rich oxygen atom on its surface. The poly (EBT) film coated GPE showed excellent electocatalytical activity towards the selectivity and sensitivity of DA in the presence of UA in the range of pH 5.0 in acetate buffer solution. The peak to peak separation between DA and UA was $158 \mathrm{mV}$. This was large enough to identify the DA and UA individually.

\section{Experimental Section}

\subsection{Reagents}

The pencil-lead rods were HB $0.5 \mathrm{~mm}$ in diameter and 6 $\mathrm{cm}$ length purchased from local bookstore. $25 \mathrm{mM}$ eriochrome black $\mathrm{T}$ stock solution was prepared in double distilled water. $10 \times 10^{-4} \mathrm{M}$ DA stock solution was prepared by dissolving in $0.1 \mathrm{M}$ perchloric acid solution. 10 $\times 10^{-3} \mathrm{M}$ stock solution of UA was prepared by dissolving in $0.1 \mathrm{M}$ sodium hydroxide solution. Sodium acetate and acetic acid were used to prepare the $0.2 \mathrm{M}$ acetate buffer solution. Chemicals mentioned above were all of analytical grade. The water used in the preparation of solutions was double distilled water.

\subsection{Apparatus}

The electrochemical experiments were carried out using a model-201 electroanalyser (EA-201 chemilink system). All the experiments were carried out in a conventional three electrochemical cell. The electrode system contained a working electrode was bare GPE and poly (EBT)

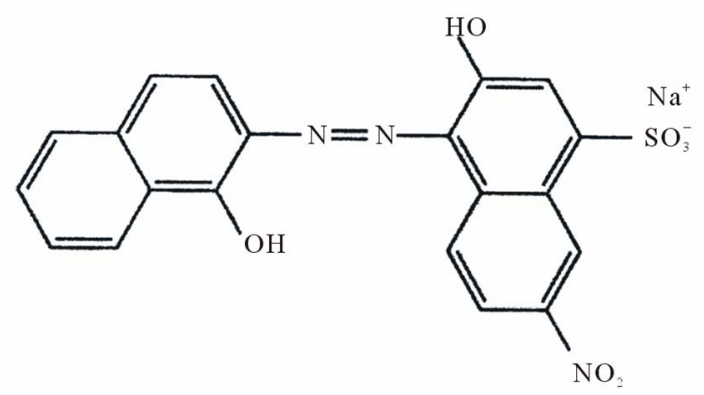

Scheme 1. Structure of eriochrome black T. filmmodified GPE ( $0.5 \mathrm{~mm}$ in diameter), a platinum wire as counter electrode and saturated calomel electrode as reference electrode.

\subsection{Preparation of Poly (EBT) Modified GPE}

The $1 \mathrm{mM}$ EBT was placed in the electrochemical cell with $0.05 \mathrm{M} \mathrm{H}_{2} \mathrm{SO}_{4}$. The GPE was scanned by immersing $3 \mathrm{~mm}$ length in that solution (from -400 to $1400 \mathrm{mV}$ ) at $100 \mathrm{mVs}^{-1}$ for 20 times. After this, the same GPE was enforced under sweeping from -400 to $1400 \mathrm{mV}$ at 100 $\mathrm{m} \cdot \mathrm{Vs}^{-1}$ for multiple cycles (20 cycles) in the solution containing $1 \mathrm{mM}$ EBT with $0.01 \mathrm{M} \mathrm{NaOH}$.

\section{Results and Discussion}

\subsection{Electrochemical Polymerization of EBT on GPE}

Figure 1 showed the cyclic voltammogram for electropolymerisation of EBT on the surface of GPE in the range from -400 to $1400 \mathrm{mV}$ at the sweep rate of $100 \mathrm{mVs}^{-1}$ at 20 multiple cycles. Before the electropolymerisation process the GPE was pretreated by scanning in the solution containing $1 \times 10^{-3} \mathrm{M}$ EBT in $0.05 \mathrm{M} \mathrm{H}_{2} \mathrm{SO}_{4}$ for 20 times in the same potential range. After this the electrode was made to undergo multiple cycles in $0.01 \mathrm{M} \mathrm{NaOH}$ containing $1 \times 10^{-3} \mathrm{M}$ EBT. During the process of multiple cycles the voltammogram has gradually descended with increase of cyclic time. This indicates that the poly (EBT) film was formed and deposited on the surface of GPE [27-29].

\subsection{Electrocatalytic Response of DA at Poly (EBT) Modified GPE}

DA being an easily oxidizable catecholamine, showed

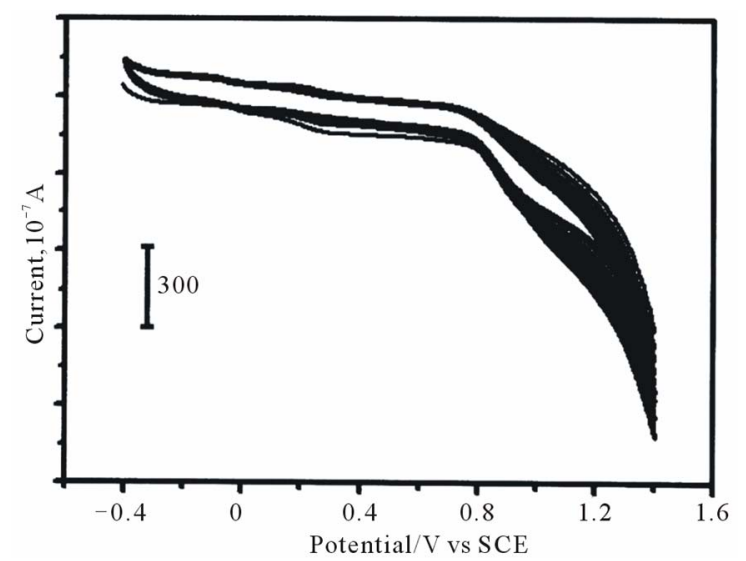

Figure 1. Cyclic voltammogram of preparation of poly (EBT) film coated GPE containing $1 \mathrm{mM}$ EBT in $0.01 \mathrm{M}$ $\mathrm{NaOH}$ at 20 cycles with sweep rate of $100 \mathrm{~m} \cdot \mathrm{Vs}^{-1}$. 
quasi-reversible voltammogram with supporting electrolyte $0.2 \mathrm{M}$ acetate buffer of $\mathrm{pH} 5.0$ at $50 \mathrm{mV} \cdot \mathrm{s}^{-1}$ scan rate for bare GPE in the potential range of -200 to $600 \mathrm{mV}$. Figure 2 showed a pair of redox peak for bare GPE (dashed line), with Epa $346 \mathrm{mV}$ and Epc $198 \mathrm{mV}$ (vs $\mathrm{SCE})$. The separation of redox peaks ( $\triangle E \mathrm{p})$ was found to be $148 \mathrm{mV}$ and the ratio of redox peak current (Ipa/Ipc) was 1.625 , which were the characteristics of a quasireversible electrode process. The formal peak potential $\left(E^{0}\right)$, which is the midpoint of Epa and Epc was obtained as $272 \mathrm{mV}$. However, at the poly (EBT) modified GPE a pair of redox peaks are obtained with strong increased in both Ipa and Ipc (solid line). The poly (EBT) modified GPE reduced the over potential which occurred for bare GPE. The Epa and Epc were located at $275 \mathrm{mV}$ and 229 $\mathrm{mV}$ respectively. At poly (EBT) modified GPE the Epa was shifted negatively upto $71 \mathrm{mV}$ and Epc was positively upto $31 \mathrm{mV}$. The $\Delta E_{\mathrm{p}}$ was found to be $40 \mathrm{mV}$, which was on accordance with a Nernst reversible behaviour and identified that number of electrons involved in the reaction was about equal to two. The ratio $(I \mathrm{pa} / \mathrm{Ipc})$ was 1.1 and the $E^{0}$ was $252 \mathrm{mV}$. The shifting of redox peak potentials and approaching of Ipa/Ipc towards 1, were shows the excellent electrocatalytic activity of poly (EBT) film coated GPE for detection of DA. Thus, the voltammogram obtained for DA at poly (EBT) modified GPE was reversible with excellent enhancement of oxidation and reduction peak currents.

\subsection{The Effect of Scan Rate}

The effect of scan rate on the anodic peak current of DA was studied at poly (EBT) modified GPE by using CV technique (Figure 3(a)). The scan rate was increased from 50 to $400 \mathrm{mV} / \mathrm{s}$. the anodic peak current was increased with increase in scan rate. The graph of Ipa vs scan rate was plotted (Figure 3(b)). The resulted graph

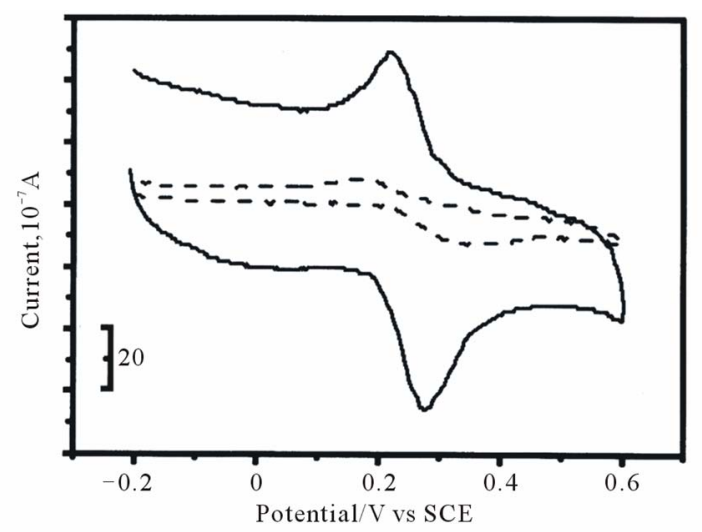

Figure 2. Cyclic voltammogram of $1 \times 10^{-4} \mathrm{M}$ DA in $0.2 \mathrm{M}$ acetate buffer solution of pH 5.0 at bare GPE (dashed line) and poly(EBT) film coated GPE (solid line).

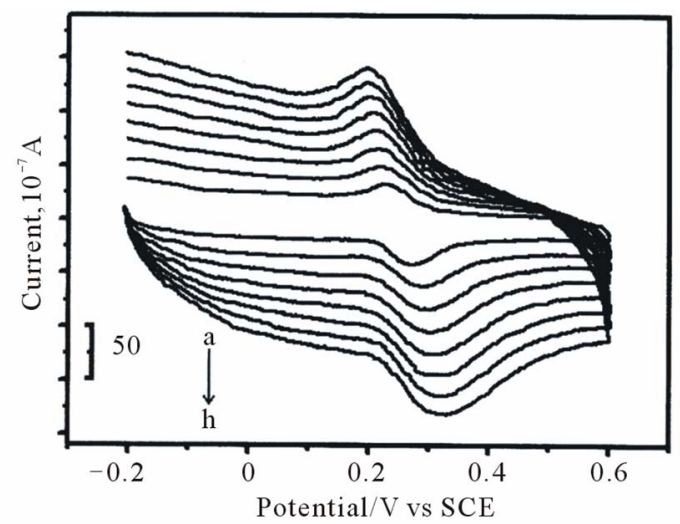

(a)

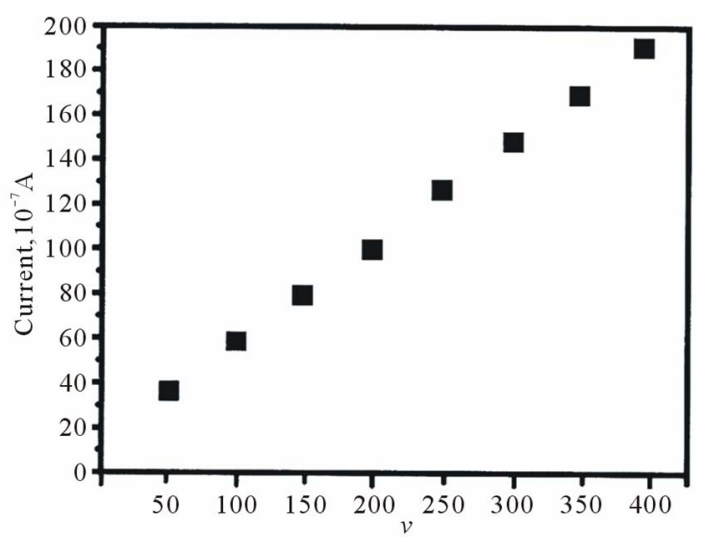

(b)

Figure 3. (a) Variation of scan rate for DA at poly (EBT) film coated GPE (a-h; $50 \mathrm{~m} \cdot \mathrm{Vs}^{-1}$ to $\left.400 \mathrm{~m} \cdot \mathrm{Vs}^{-1}\right)$. (b) Graph of current vs square root of scan rate.

showed excellent linearity with correlation co-efficient of 0.9997 . This result showed that the electrode process was adsorption controlled.

\subsection{Effect of $\mathrm{pH}$}

The electrochemical response of DA at poly (EBT) film coated GPE is generally $\mathrm{pH}$ dependent. The voltammograms of DA were recorded at $0.2 \mathrm{M}$ acetate buffer solutions of different $\mathrm{pH}$ by cyclic voltammetric method. Figure 4(a) demonstrates the $\mathrm{pH}$ dependence of $\mathrm{DA}$ at poly (EBT) film coated GPE at sweep rate of $50 \mathrm{mV} \cdot \mathrm{s}^{-1}$. The both anodic and cathodic peak potentials were shifted to less positive side with increasing in the $\mathrm{pH}$ values. The anodic peak potential of DA shifted from $331 \mathrm{mV}$ to $249 \mathrm{mV}$ with respect the $\mathrm{pH}$ from 3.8 to 5.6. The potential diagram was constructed by plotting the graph of calculated $\mathrm{E}^{0}$ vs $\mathrm{pH}$ of the solution (Figure 4(b)). The graph has good linearity with a slope of 45 $\mathrm{mV} / \mathrm{pH}$ this behaviour is nearly obeyed the Nernst Equation for two electron and two proton transfer reaction. 


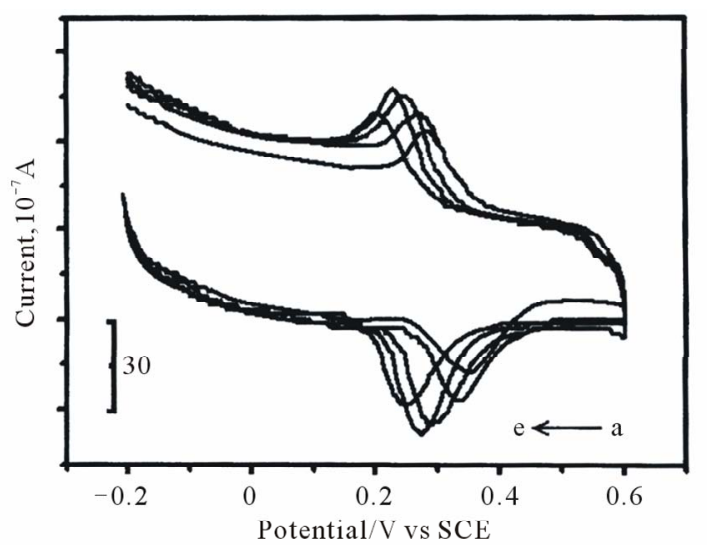

(a)

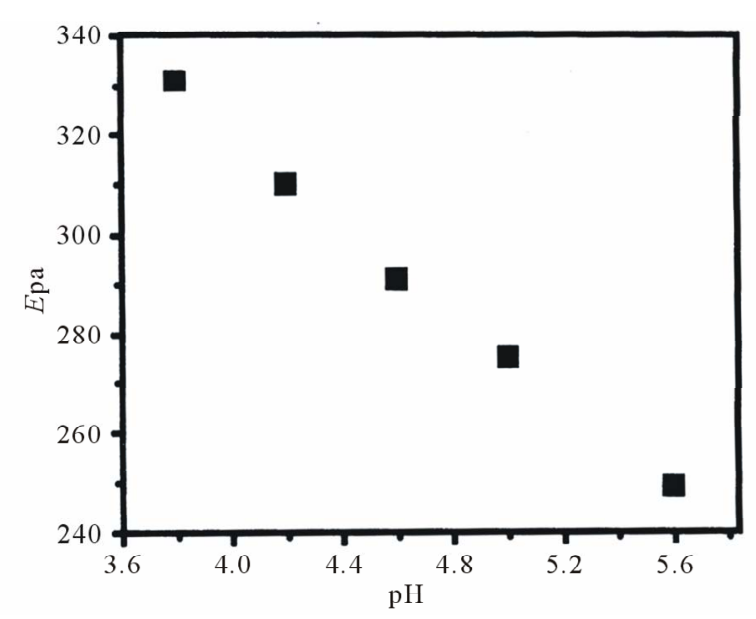

(b)

Figure 4. (a) Cyclic voltammogram of DA at different pH (a - e; 3.8, 4.2, 4.6, 5.0, 5.6 pH). (b) Graph of $\mathrm{E}^{0} \mathrm{vs} \mathrm{pH}$.

\subsection{Effect of Concentration of DA}

The electrocatalytic oxidation of DA was carried out by varying its concentration at poly (EBT) modified GPE. Figure 5(a) showed that, by increasing the concentration of DA, the electrochemical anodic and cathodic peak current goes on increasing with shifting Epa towards positive and $E$ pc towards negative direction. DA from $0.1 \times 10^{-3}$ to $0.5 \times 10^{-3}$ concentrations showed the Epa was increased from $275 \mathrm{mV}$ to $305 \mathrm{mV}$. The graph of anodic peak current vs concentration of DA was plotted (Figure 5(b)). The anodic peak current was proportional to concentration of DA in the above range.

\subsection{Simultaneous Determination of DA and UA by Cyclic Voltammetry}

UA is present along with DA in mammalian brain. The concentration of UA is much higher than that of DA. Since, the oxidation potential of UA is nearly same as

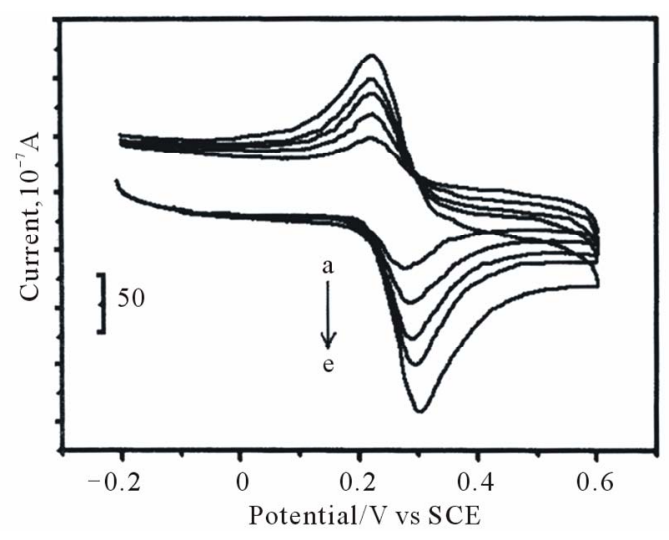

(a)

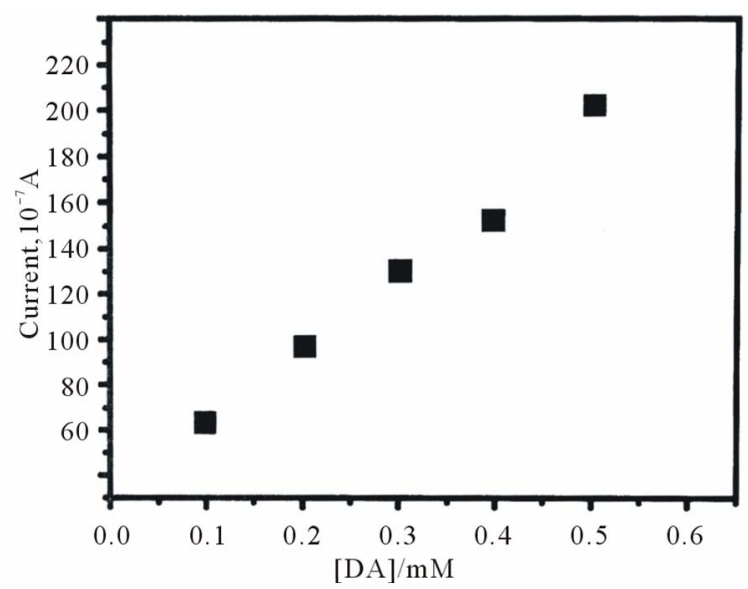

(b)

Figure 5. (a) Cyclic voltammogram of DA at different concentration (a-e; 0.1, 0.2, 0.3, 0.4, $0.5 \times 10^{-3} \mathrm{M}$ ). (b) Graph of current vs concentration of DA.

that of DA result in an overlapped voltammetric response at bare CPE. However, the poly (EBT) modified GPE has ability to separate the oxidation peak potentials of DA and UA. Figure 6(a) showed the voltammograms were recorded for individual UA at both bare poly (EBT) film modified GPE at sweep rate of $50 \mathrm{mV} \cdot \mathrm{s}^{-1}$ in the potential range from $-200 \mathrm{mV}$ to $700 \mathrm{mV}$. The voltammogram of UA has Epa, which was found to be $452 \mathrm{mV}$ in a pH 5.0 acetate buffer solution at bare GPE (dashed line). However the Epa was shifted at $424 \mathrm{mV}$ at poly (EBT) modified GPE (solid line) with strong enhancement of Ipa. The plot of Epa vs pH was linear and slope was found to be $-0.054 \mathrm{mV}$. The Ipa of uric acid was proportional to the $v$ with correlation coefficient (r) 0.9995 (data was not shown).

The Figure 6(b) showed the voltammogram for solution containing mixture of both $0.1 \times 10^{-3} \mathrm{DA}$ and $0.5 \times$ $10^{-3} \mathrm{M}$ UA in pH 5.0 acetate buffer solution at sweep rate of $50 \mathrm{mV} \cdot \mathrm{s}^{-1}$ from potential range 0 to $700 \mathrm{mV}$. The bare GPE (dashed line) showed only one broad anodic 


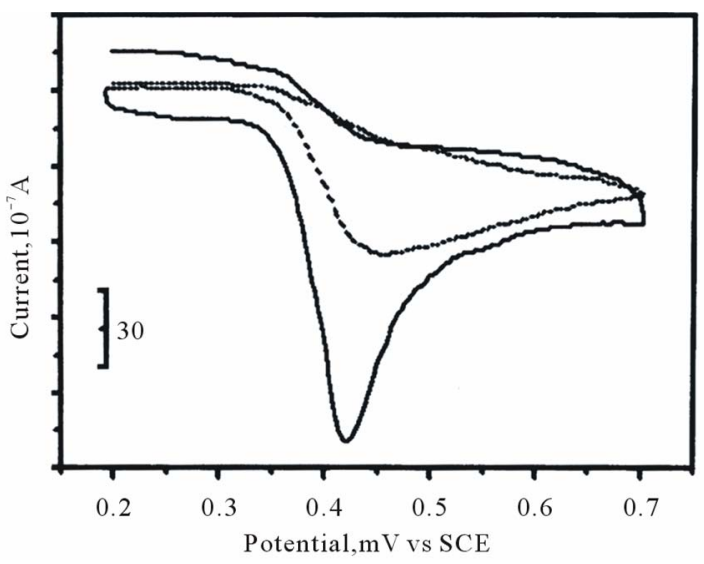

(a)

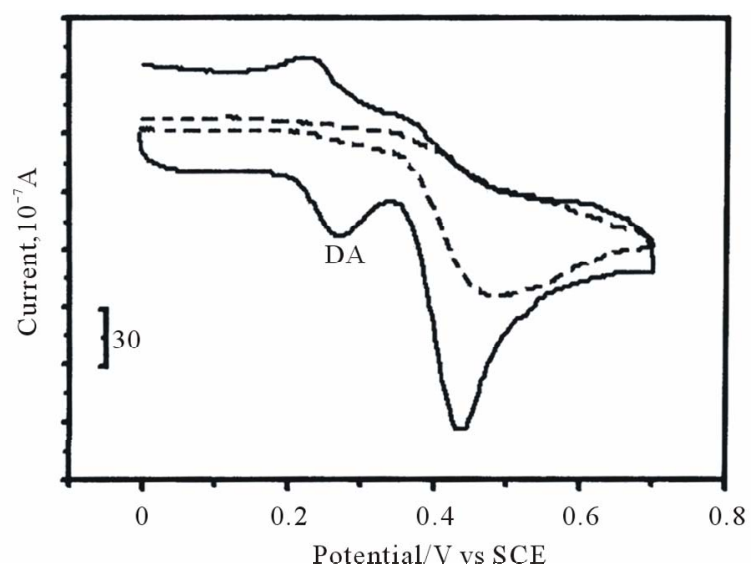

(b)

Figure 6. (a) Cyclic voltammogram of $0.5 \times 10^{-3} \mathrm{M}$ UA at bare GPE (dashed line) and at poly (EBT) film coated GPE (solid line) in $0.2 \mathrm{M}$ acetate buffer solution of pH 5.0. (b) Simultaneous determination of $1 \times 10^{-4} \mathrm{M}$ DA and $0.5 \times$ $10^{-3} \mathrm{M}$ UA at bare GPE (dashed line) and at poly (EBT) film coated GPE (solid line).

peak but not cathodic peak. The poly (EBT) modified GPE has able to separate the oxidation peaks of DA and UA by showing two well separated anodic peaks and one cathodic peak (solid line). The electrocatalytical anodic peak of DA was obtained at $271 \mathrm{mV}$ and UA was found to be at $429 \mathrm{mV}$. The cathodic peak for dopamine was found to be $235 \mathrm{mV}$. The separation between DA-UA was found to be $158 \mathrm{mV}$.

\subsection{Simultaneous Detection of DA and UA by Differential Pulse Voltammetry}

DPV was used for the determination of DA and UA at poly (EBT) modified GPE because of its higher current sensitivity and better resolution than CV. The simultaneous study was carried out in the potential range from 0 to $600 \mathrm{mV}$ (Figure 7(a)). The DPV showed the simultaneous

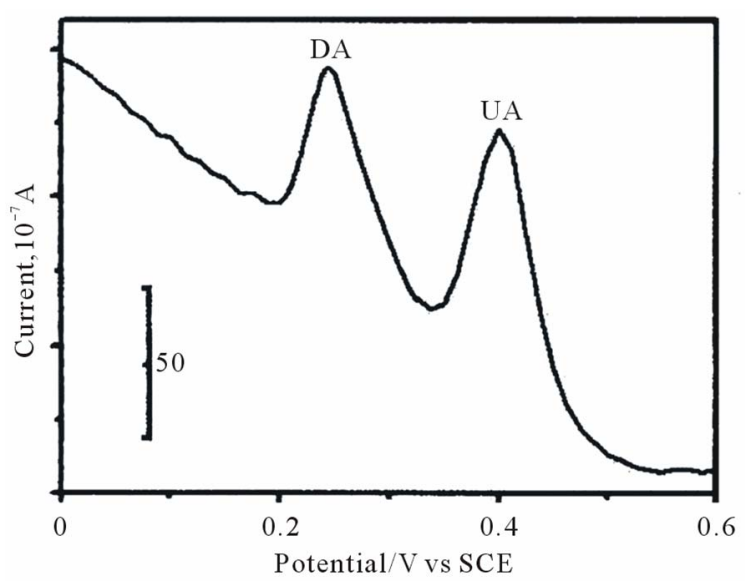

(a)

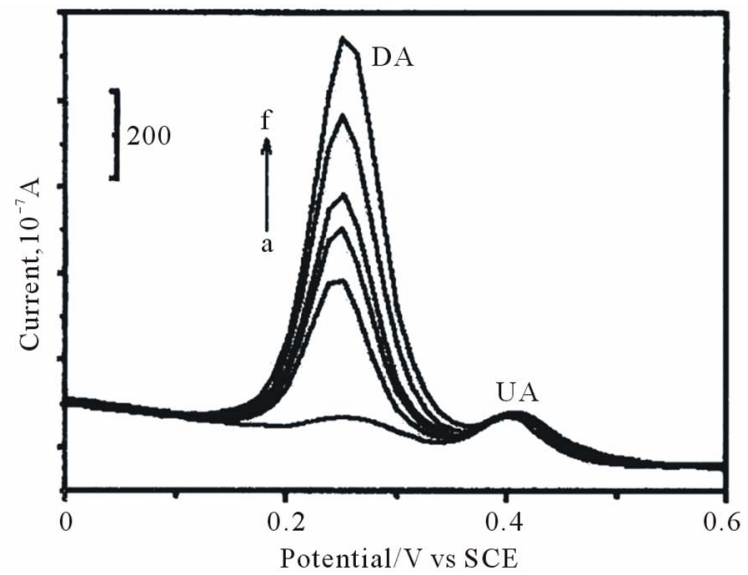

(b)

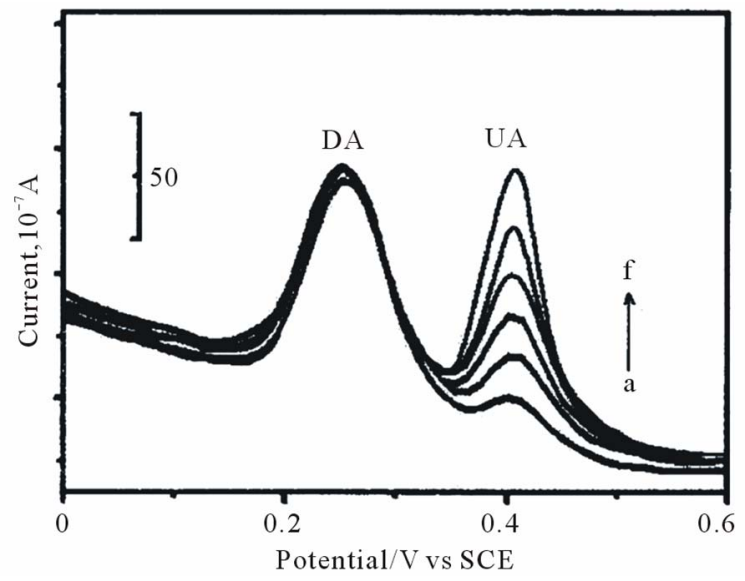

(c)

Figure 7. (a) Differential pulse voltammogram for simultaneous detection of $0.1 \mathrm{mM} \mathrm{DA}$ and $0.5 \mathrm{mM} \mathrm{UA}$ at poly (EBT) film coated GPE. (b) DPVs of (a-f; $0.1,0.15,0.17,0.2$, 0.25 and $\left.0.3 \times 10^{-3} \mathrm{M}\right) \mathrm{DA}$ in 0.2 $\mathrm{M}$ ABS of pH 5.0 in the presence of $1 \times 10^{-3} \mathrm{M}$ UA at poly (EBT) film modified GPE. (c) DPVs of (a-f; 0.2, 0.4, 0.6, 1.1, 1.6 and $2.0 \times 10^{-3} \mathrm{M}$ ) UA in $0.2 \mathrm{M}$ ABS of pH 5.0 in the presence of $0.1 \times 10^{-3} \mathrm{M}$ DA at poly (EBT) film modified GPE. 
determination of DA and UA with well separated two anodic peaks corresponding to their oxidation could be possible at poly (EBT) modified GPE. The $0.1 \times 10^{-3} \mathrm{M}$ DA showed its Epa at 252 and $0.5 \times 10^{-3} \mathrm{M}$ UA was at $414 \mathrm{mV}$. The peak separation between DA and UA was $162 \mathrm{mV}$ which was greater when comparing to peak separation occurred by $\mathrm{CV}$.

The simultaneous determination of DA and UA in the mixture was carried out at poly (EBT) film coated GPE when concentration of one species changed, whereas another one remained kept constant. From the Figure 7(b), it can be seen that the peak current of DA was proportional to its concentration, which was increased from $0.1 \times 10^{-3} \mathrm{M}$ to $0.3 \times 10^{-3} \mathrm{M}$ when keeping the concentration of UA $1 \times 10^{-3} \mathrm{M}$. There was no change in the peak current and peak potential occurred for UA. Similarly in the Figure 7(c) keeping the concentration of DA constant, the UA concentration was varied from $0.2 \times$ $10^{-3} \mathrm{M}$ to $2.0 \times 10^{-3} \mathrm{M}$. The oxidation peak current of UA increases with increase in its concentrations. The detection limit was calculated and found to be $0.08 \mu \mathrm{M}$ for DA concentration [36].

\subsection{Analytical Application}

The modified electrode was applied to the determination of dopamine hydrochloride injection. The DA injection sample purchased from sterile specialities India Private Ltd with a specified content of DA of $40.0 \mathrm{mg} / \mathrm{mL}$. The sample was used after suitable dilution. The results were shown in Table 1. The recovery and R.S.D. were acceptable, showing that the proposed methods could be efficiently used for the determination of DA in injections with recovery in the range $99.25 \%-101.25 \%$.

\section{Conclusions}

In this work, poly (EBT) film coated GPE was used to investigate the electrochemical response of an interesting neurotransmitter DA. The poly (EBT) film coated GPE enhanced both anodic and cathodic peak current strongly. The poly (EBT) film coated GPE showed excellent selective and electrocatalytic activity towards the oxidation of DA in the presence of and UA. The poly (EBT) film coated GPE has very low detection limit $0.08 \mu \mathrm{M}$. Hence,

Table 1. Detection of DA in injection samples $(n=5)$.

\begin{tabular}{ccccc}
\hline Sample & $\begin{array}{c}\text { Content } \\
(\mathrm{mg} / \mathrm{mL})\end{array}$ & $\begin{array}{c}\text { Found } \\
(\mathrm{mg} / \mathrm{mL})\end{array}$ & $\begin{array}{c}\text { RSD } \\
(\%)\end{array}$ & $\begin{array}{c}\text { Recovery } \\
(\%)\end{array}$ \\
\hline 1 & 4.0 & 3.97 & 2.4 & 99.25 \\
2 & 4.0 & 3.99 & 2.0 & 99.75 \\
3 & 4.0 & 4.05 & 2.2 & 101.25 \\
\hline
\end{tabular}

poly (EBT) modified GPE is acting as a good sensor for the detection of DA. We hope our modified electrode can be used for investigation of other neurotransmitters. The proposed methods can be applied to the detection of DA in injection.

\section{References}

[1] A. G. Paul and W. R. Mark, "In Vivo Voltammetric Measurement of Evoked Extracellular Dopamine in the Rat Basolateral Amygdaloid Nucleus," Journal of Physiology, Vol. 478, No. 2, 1994, pp. 239-249.

[2] J. De Olmos, G. F. Alheid and C. A. Beltramino, "Amygdala. In the Rat Nervous System," In: G. Paxinos, Ed., Forebrain and Midbrain, Academic press, San Diego, Vol. 1, 1985, pp. 223-334.

[3] O. Gilbert, B. E. K. Swamy, U. Chandra and B. S. Sherigara, "Simultaneous Detection of Dopamine and Ascorbic Acid Using Polyglycine Modified Carbon Paste Electrode: A Cyclic Voltammetric Study," Journal of Electroanalytical Chemistry, Vol. 636, No. 1-2, 2009, pp. 80-85. doi:10.1016/i.jelechem.2009.09.016

[4] O. Gilbert, B. E. K. Swamy, U. Chandra and B. S. Sherigara, "Electrocatalytic Oxidation of Dopamine and Ascorbic Acid at Poly (Eriochrome Black-T) Modified Carbon Paste Electrode," International Journal of Electrochemical Science, Vol. 4, No. 4, 2009, pp. 582-591.

[5] R. R. Naik, B. E. K. Swamy, U. Chandra, E. Niranjana, B. S. Sherigara and H. Jayadevappa, "Separation of Ascorbic Acid, Dopamine and Uric Acid by Acetone/Water Modified Carbon Paste Electrode: A Cyclic Voltammetric Study," International Journal of Electrochemical Science, Vol. 4, No. 6, 2009, pp. 855-862.

[6] S. S. Shankar, B. E. K. Swamy, U. Chandra, J. G. Manjunatha and B. S. Sherigara, "Simultaneous Determination of Dopamine, Uric Acid and Ascorbic Acid with Ctab Modified Carbon Paste Electrode," International Journal of Electrochemical Science, Vol. 4, No. 4, 2009, pp. 592-601.

[7] M. Pandurangachar, B. E. K. Swamy, U. Chandra and B. S. Sherigara, "Simultaneous Determination of Dopamine, Ascorbic Acid and Uric Acid at Poly (Patton and Reeder's) Modified Carbon Paste Electrode," International Journal of Electrochemical Science, Vol. 4, No. 5, 2009, pp. 672-683.

[8] G. H. Zhao, M. F. Li and M. L. Li, "Differential Pulse Voltammetric Determination of Dopamine with Coexistence of Ascorbic Acid on Boron-Doped Diamond Surface," Central European Journal of Chemistry, Vol. 5, No. 4, 2007, pp. 1114-1123. doi:10.2478/s11532-007-0049-1

[9] S. Sarre, Y. Michotte, P. Herregodts, D. Deleu, N. D. Klippel and G. Ebinger, "High-Performance Liquid Chromatography with Electrochemical Detection for the Determination of Levodopa, Catecholamiine and their Metabolites in Rat Brain Dialysates," Journal of Chromatography, Vol. 575, No. 2, 1992, pp. 207-212.

[10] C. L. Guan, J. Ouyang, Q. L. Li, B. H. Liu and W. R. G. 
Baeyens, "Simultaneous Determination of Catecholamine by Ion Chromatography with Direct Conductivity Detection," Talanta, Vol. 50, No. 6, 2000, pp. 1197-1203. doi:10.1016/S0039-9140(99)00225-8

[11] U. Chandra, B. E. K. Swamy, O. Gilbert, M. Pandurangachar and B. S. Sherigara, "Voltammetric Resolution of Dopamine in Presence of Ascorbic Acid at Polyvinyl Alcohol Modified Carbon Paste Electrode," International Journal of Electrochemical Science, Vol. 4, No. 10, 2009, pp. 1479-1488.

[12] F. B. Salem, "Spectrophotometric and Titrimetric Determination of Catecholamines," Talanta, Vol. 34, No. 9, 1987, pp. 810-812. doi:10.1016/0039-9140(87)80101-7

[13] S. Wei, Y. Maoxia and J. Kui, "Electrocatalytic Oxidation of Dopamine at an Ionic Liquid Modified Carbon Paste Electrode and its Analytical Application," Analytical Bioanalytical Chemisry, Vol. 389, No. 4, 2007, pp. 1283-1291. doi:10.1007/s00216-007-1518-2

[14] J. Premkumar and S. B. Khoo, "Electrocatalytic Oxidations of Biological Molecules (Ascorbic Acid and Uric acids) at Highly Oxidized Electrodes," Journal of Electroanalytical Chemistry, Vol. 576, No. 1, 2005, pp. 105-112. doi:10.1016/j.jelechem.2004.09.030

[15] F. Arslan, "An Amperometric Biosensor for Uric Acid Determination Prepared from Uricase Immobilized in Polyaniline-Polypyrrole Film," Sensors, Vol. 8, No. 9, 2008, pp. 5492-5500. doi:10.3390/s8095492

[16] J. M. Zen and J. S. Tang, "Square-Wave Voltammetric Determination of Uric Acid by Catalytic Oxidation at a Perfluorosulfonated Ionomer/Ruthenium Oxide Pyrochlore Chemically Modified Electrode," Analytical Chemistry, Vol. 67, No. 11, 1995, pp. 1892-1895. doi:10.1021/ac00107a021

[17] M. H. Alderman. "Uric Acid and Cardiovascular Risk," Current Opinion in Pharmacology, Vol. 2, No. 2, 2002, pp. 126-130. doi:10.1016/S1471-4892(02)00143-1

[18] J. S. Rodman, J. J. Williams and C. M. Peterson, "Dissolution of Uric Acid Calculi," Journal of Urology, Vol. 131, No. 6, 1984, pp. 1039-1044.

[19] C. R. Raj and T. Ohsaka, "Voltammetric Detection of Uric Acid in the Presence of Ascorbic Acid at a Gold Electrode Modified with a Self-Assembled Monolayer of Heteroaromaticthiol," Journal of Electroanalytical Chemistry, Vol. 540, No. 2, 2003, pp. 69-77. doi:10.1016/S0022-0728(02)01285-8

[20] S. A. Wring and J. P. Hart, "Chemically Modified, Carbon-Based Electrodes and Their Application as Electrochemical Sensors for the Analysis of Biologically Important Compounds," Analyst, Vol. 117, No. 8, 1992, pp. 1215-1229. doi:10.1039/an9921701215

[21] O. Gilbert, U. Chandra, B. E. K. Swamy, M. Panduranga Char, C. Nagaraj and B. S. Sherigara. "Poly (Alanine) Modified Carbon Paste Electrode for Simultaneous Detection of Dopamine and Ascorbic Acid," International Journal of Electrochemical Science, Vol. 3, No. 10, 2008, pp. 1186-1195.

[22] C. Y. Liu, L. Z. Yang, F. Song, L. Y. Jiang and G. H. Lu, "Simultaneous Determination of Dopamine and Uric Ac- id at 2-Amino-5-mercapto-[1,3,4] triazole Self-Assembled Monolayers Gold Electrode," Chinese Chemical Letters, Vol. 16, No. 2, 2005, pp. 237-240.

[23] E. M. Strochkova, Y. I. Tur'yan, I. Kuselman and A. Shenhar, "Simultaneous Voltammetric Determination of Uric and Ascorbic Acids in Urine," Talanta, Vol. 44, No. 10, 1997, pp. 1923-1928. doi:10.1016/S0039-9140(97)00087-8

[24] B. Gabriela, V. S. Tatiana, K. Martin, V. Radko and K. Vladimir, "Optimalization of Poly (Neutral Red) Coatedwire Electrode for Determination of Citrate in Soft Drinks," Sensors, Vol. 8, No. 2, 2008, pp. 594-606. doi: $10.3390 / \mathrm{s} 8020594$

[25] M. K. Sarah, R. Gaia, P. M. Colm, D. C. Jennifer, J. K. Sarah, K. B. O'Brien, A. S. Pier, P. L. John and D. O'Neill Robert. "Modifications of Poly (o-phenylenediamine) Permselective Layer on Pt-Ir for Biosensor Application in Neurochemical Monitoring." Sensors, Vol. 7, 2007, pp. 420-437. doi:10.3390/s7040420

[26] U. Chandra, O. Gilbert, B. E. K. Swamy, Y. D. Bodke and B. S. Sherigara, "Electrochemical Studies of Eriochrome Black T at Carbon Paste Electrode and Immobilized by SDS Surfactant: A Cyclic Voltammetric Study," International Journal of Electrochemical Science, Vol. 3, No. 9, 2008, pp. 1044-1054.

[27] Y. Hong, S. Yuanyuan, L. Xinhua, T. Yuhai, L. Ailin, Li. Guangwen, L. Wei and Z. Shaobo, "Selective Determination of Epinephrine in the Presence of Ascorbic Acid and Uric Acid by Electrocatalytic Oxidation at Poly (Eriochrome Black T) Film-Modified Glassy Carbon Electrode," Analytical Science, Vol. 23, No. 6, 2007, pp. 677-682. doi:10.2116/analsci.23.677

[28] L. Xinhua, L. Wei, Y. Hong, S. Yuanyuan, H. Liying and Z. Yanjie, "Electrocatalytic Response and Determination of Noradrenaline in the Presence of 1-Ascorbic and Uric acids with Poly (Erioichrome Black T)-Modified Electrode," Collection of Czechoslovak Chemical Communication, Vol. 72, No. 9, 2007, pp. 1177-1188. doi: $10.1135 / \operatorname{cccc} 20071177$

[29] Y. Hong, S. Yuanyuan, L. Xinhua, T. Yuhai and H. Liying, "Electrochemical Characterization of Poly (Erichrome Black T) Modified Glassy Carbon Electrode and its Application to Simultaneous Determination of Dopamine, Ascorbic Acid and Uric Acid," Electrochimica Acta, Vol. 52, No. 20, 2007, pp. 6165-6171. doi:10.1016/j.electacta.2007.04.013

[30] M. Ozsoz, A. Erdem, P. Kara, K. Kerman and D. Ozkan, "Electrochemical Biosensor for the Detection of Interaction Between Arsenic Trioxide and DNA Based on Guanine Signal," Electroanalysis, Vol. 15, No. 7, 2003, pp. 613-619. doi:10.1002/elan.200390077

[31] S. Veronika, P. Jiri, H. Ladislav, K. Sona, P. V. A. Jitka, P. David, B. Petre, B. Miroslava, H. Ales and K. Rene, "Electrochemical Sensors for Detection of Acetylsalicylic Acid," Sensors, Vol. 6, No. 11, 2006, pp. 1483-1497. doi: $10.3390 / \mathrm{s} 6111483$

[32] O. Levent, S. Mutlu and S. Yucel, "Electrochemical Preparation of a Molecularly Imprinted Polypyrrole- 
modified Pencil Graphite Electrode for Determination of Ascorbic Acid," Sensors, Vol. 8, No. 9, 2008, pp. 57925805. doi: $10.3390 / \mathrm{s} 8095792$

[33] M. Fojta, L. Havran, S. Billova, P. Kostecka, M. Masarik and R. Kizek. "Two-Surface Strategy in Electrochemical DNA Hybridization Assays: Detection of Osmium-Labeled Target DNA at Carbon Electrodes," Electroanalysis, Vol. 15, No. 5-6, 2003, pp. 431-440. doi:10.1002/elan.200390050

[34] J. Wang and A. N. Kawde, "Pencil-Based Renewable Biosensor for Label-Free Electrochemical Detection of DNA Hybridization," Analytica Chimica Acta, Vol. 431, No. 2, 2001, pp. 219-224.
doi:10.1016/S0003-2670(00)01318-0

[35] U. Chandra, B. E. K. Swamy, O. Gilbert, M. Pandurangachar, S. Reddy, S. S. Shankar and B. S. Sherigara, "Poly (Amaranth) Film Based Sensor for Resolution of Dopamine in the Presence of Uric Acid: A Voltammetric Study," Chinese Chemical Letters, Vol. 21, No. 12, 2010, pp. 1490-1492. doi:10.1016/j.cclet.2010.07.016

[36] U. Chandra, B. E. K. Swamy, O. Gilbert and B. S. Sherigara, "Voltammetric Resolution of Dopamine in the Presence of Ascorbic Acid and Uric Acid at Poly (Calmagite) Film Coated Carbon Paste Electrode," Electrochimica Acta, Vol. 55, No. 24, 2010, pp. 7166-7174. doi:10.1016/j.electacta.2010.06.091 